\title{
Wet casting of multiple mix horizontally layered concrete elements
}

\section{Citation:}

Brault, A., \& Lees, J. M. (2020). Wet casting of multiple mix horizontally layered concrete elements. Construction and Building Materials, 247, 118514

https://doi.org/10.1016/i.conbuildmat.2020.118514

Version:

Accepted for publication

Additional Information:

The accepted manuscript and additional data related to this publication are available from the University of Cambridge's institutional repository:

https://www.repository.cam.ac.uk/handle/1810/303683

https://doi.org/10.17863/CAM.49680

Please cite the published version. 
Brault, A. \& Lees, J. M. (2020). Wet casting of multiple mix horizontally layered concrete elements Construction and Building Materials. 247, 118514

https://doi.org/10.1016/j.conbuildmat.2020.118514

Wet casting of multiple mix horizontally layered concrete elements

Andre Brault ${ }^{1}$ and $*$ Janet M. Lees ${ }^{1}$

${ }^{1}$ Department of Engineering, University of Cambridge, Cambridge, CB2 1PZ, UK

*Corresponding author, E-mail: jml2@eng.cam.ac.uk 
Brault, A. \& Lees, J. M. (2020). Wet casting of multiple mix horizontally layered concrete elements Construction and Building Materials. 247, 118514

https://doi.org/10.1016/i.conbuildmat.2020.118514

\begin{abstract}
Functionally graded concrete, where multiple mixes are layered in structural elements, is a promising technology for minimising cement use. However, a challenge when fabricating weton-wet graded concrete is the control of the fresh state deformations of multiple mixes cast into the same mould. Horizontally cast elements with two different concrete mix layers were investigated to ascertain the influence of mix density, workability and layer sequence on the intended material placement. Horizontal layers were achievable unless the workability of the top layer was much stiffer than that of the bottom, or the top layer was denser and both mixes were fluid. The findings underpin opportunities for the exploitation of lower carbon materials and cement efficiency.
\end{abstract}

\title{
KEYWORDS
}

Concrete; Rheology; Slump; Functionally graded concrete; Multi-layered casting; Light weight aggregates; Cement. 
Brault, A. \& Lees, J. M. (2020). Wet casting of multiple mix horizontally layered concrete elements Construction and Building Materials. 247, 118514

https://doi.org/10.1016/i.conbuildmat.2020.118514

\section{INTRODUCTION}

Cement is a key constituent of concrete, the most used construction material in the world. The production of cement alone accounts for 5-7\% of global human-made carbon dioxide emissions [1],[2]. With projections that the number of buildings will double by 2060 [3], it is crucial that we pursue technologies that allow us to meet building and infrastructure demands while ensuring that cement is used as efficiently as possible.

Structural concrete elements have traditionally been cast with a single homogenous concrete mix. By contrast, Functionally Graded Concrete (FGC) elements explore the idea of utilizing multiple mixes in a single element. These mixes are spatially organized within the volume of a structural element such that the location of each unique mix is determined to satisfy performance requirements. For example, to improve the durability [4],[5],[6],[7] high performance cementitious materials are located in peripheral regions to reduce permeability and improve the cracking resistance. To enhance the mechanical response, flexural members are designed with a layer of strain-hardening fibre reinforced concrete for crack width reduction [4].

In recent years, functional grading has experienced a resurgence as a means to develop more environmentally sensitive concrete structures. This has typically been done by reducing either the cement content [8] via locating concrete mixes with high cement contents only where they are truly required, or the overall element weight [9] by concentrating light weight mixes wherever possible. The decarbonisation opportunities that FGC present are expected to grow as low carbon concretes improve and gain wider acceptance. Low carbon mixes offer significant $\mathrm{CO}_{2}$ emission reductions [10] but are not always suitable for certain applications if they are the only mix used in an element. But if low carbon mixes are judiciously combined with other mixes in FGC solutions, these limitations can potentially be overcome to expand the 
Brault, A. \& Lees, J. M. (2020). Wet casting of multiple mix horizontally layered concrete elements Construction and Building Materials. 247, 118514

https://doi.org/10.1016/i.conbuildmat.2020.118514

landscape for utilisation. To exploit this opportunity, FGC manufacturing processes must be compatible with concrete mixes that possess a variety of properties, largely in terms of workability, density, and aggregate size/type.

Digital concrete manufacturing developments [11], such as 3D printing [12] or multimix spraying [9], present exciting options for constructing FGC elements. However, the concrete mixes involved typically need to be fine-tuned to suit the manufacturing processes in terms of properties such as the rheology [13] and the maximum aggregate size [14],[15],[16]. This can increase the amount of binder content in the mix and lead to higher cement contents. The associated construction processes entail either no formwork (3D printing) or bespoke surface forms (spraying). If instead conventional mould filling formwork is retained, bulk casting techniques [17] can be used. The resulting accommodation of a broad scope of concrete fluidities and concrete types in the manufacturing process allows one to then truly design the concrete mixes in the FGC element for hardened performance and environmental impact rather than the strict requirements of the fabrication process itself.

By accepting the use of formwork, the realization of FGC can be approached in a spectrum of ways that range from wet-on-hard casting to wet-on-wet casting [18]. Wet-on-hard is described as the casting of a fresh layer of concrete on top of, or beside, a previously placed volume of concrete that has had sufficient time to set. This process is commonly used today where in-situ concrete is placed against precast elements [19],[20],[21]. A key advantage of the wet-on-hard approach is that the hardened FGC geometry ends up as intended. However, this method increases production times, and the interface adhesion between concrete layers can be negatively impacted due to a lack of cement hydration and/or intermixing [22],[23]. Conversely, wet-on-wet casting is a process where multiple mixes are cast into the same element within a small timeframe, thereby allowing the mixes to harden somewhat together. 
Brault, A. \& Lees, J. M. (2020). Wet casting of multiple mix horizontally layered concrete elements Construction and Building Materials. 247, 118514

https://doi.org/10.1016/i.conbuildmat.2020.118514

Horizontally layered FGC elements have been fabricated with a short delay (20-60 minutes) between the deposition of each concrete mix layer [4],[5],[7],[24]. The slight delay between castings (at least 20 minutes) allows for the base layer to experience a degree of thixotropic structuration prior to receiving a concrete layer on top, ensuring that the hardened layer geometries intended by the researchers were achieved. This approach captures the mechanical benefits of each mix undergoing cement hydration and shrinkage essentially in parallel. However, thixotropic structuration has been found to reduce the mechanical shear strength of a smooth interface between sequential layers of horizontally cast self-compacting concrete by $30-40 \%$ for a delay time of 60 mins [25]. There is thus a need for more rigorous definitions of the mix parameters, rheological characteristics, density differentials, processing drivers and allowable setting times to inform what constitutes an acceptable delay between layers to attain a specified hardened state performance.

'Immediate' wet-on-wet casting of layers (less than $\sim 1$ minute delay between pours) can eliminate these mechanical reductions by avoiding structurisation and invoking cement hydration across layers [23]. Shorter production times are a further advantage. However, ‘immediate’ wet-on-wet casting presents a clear challenge: the fluid nature of the fresh concrete mixes that are placed into the same mould at essentially the same time may lead to hardened layered geometries that significantly deviate from the intended design. For example, it has been shown that the placement of side-by-side vertical columns of two different mixes may become unstable [26]. Figure 1 presents a schematic of this problem for two horizontal layers cast into the same mould. The different mix densities, time-dependent rheologies, and process controlled factors can all cause the mixes to flow in unintended manners that may or may not result in a satisfactory element layout. For example, a denser top layer concrete may create deviations at the interface if both concrete mixes are quite fluid. So while a designer may wish to deposit 
Brault, A. \& Lees, J. M. (2020). Wet casting of multiple mix horizontally layered concrete elements Construction and Building Materials. 247, 118514

https://doi.org/10.1016/i.conbuildmat.2020.118514

different mixes in fairly regular horizontal layers, this is only achievable if the concrete properties and fresh state behaviours are compatible and their interactions are well understood.

Intended geometry

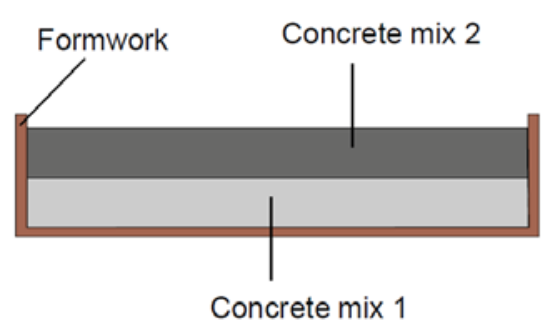

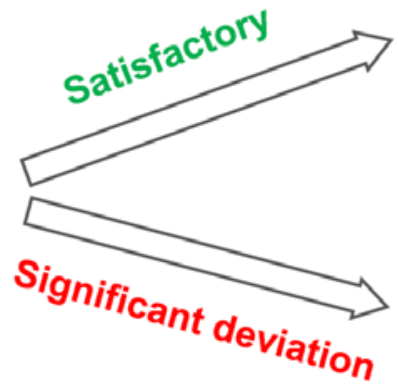

Hardened results

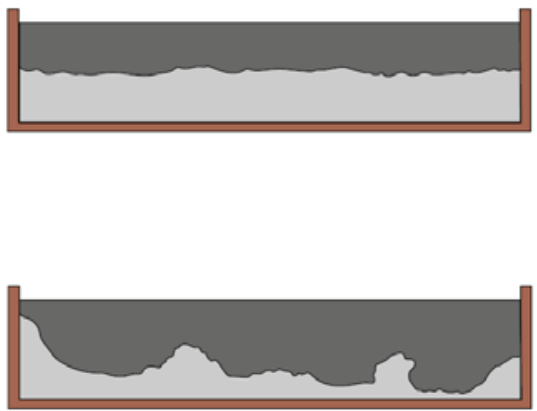

Figure 1. Schematic of a horizontally layered FGC with two different concrete mixes demonstrating potential hardened outcomes compared to the intended geometry.

There has been no research to date to address the specific challenge of understanding the local flow of concrete at the interfaces between multiple mixes in a horizontally layered FGC. Yet the ability to isolate mix combinations that lead to satisfactory hardened layer geometries underpins the adoption of wet-on-wet casting of horizontally layered FGC. The aim of this work is therefore to investigate horizontally layered FGC elements in the fresh state to determine the effects of mix density and workability on the profile of the interface between different concrete mixes, and to discover a framework for predicting compatible mix combinations for wet casting horizontal layers. The underlying principles provide a means to identify a wide breadth of non-conventional and low-carbon concrete mixes that could be used in combination with other mixes to maximise environmental and performance enhancements, while also maintaining fast production times and optimal interface adhesion.

\section{EXPERIMENTAL PROGRAM}

Concrete elements comprised of two horizontally cast concrete layers with different mixes and layer sequences were investigated. The rheology/workability and density of the 
Brault, A. \& Lees, J. M. (2020). Wet casting of multiple mix horizontally layered concrete elements Construction and Building Materials. 247, 118514

https://doi.org/10.1016/i.conbuildmat.2020.118514

concrete layers were varied to investigate their effects on the mix distribution in the hardened layered specimens. The concrete density was modified by incorporating lightweight aggregates that were roughly $50 \%$ of the specific gravity of the normal aggregates used, while the concrete workability was adjusted by including various doses of Super Plasticizer (SP), as a technique for increasing the slump of otherwise identical mixes [27]. Each mix was used as either a top or bottom layer to ascertain the influence of the stacking sequence.

\subsection{Concrete Mixes}

A total of 18 concrete mixes were designed with different densities and rheologies. The mix names, constituents, density measurements, and slump measurements are presented in Table 1. Half of the mixes were termed as normal concrete (NC), which contained standard coarse aggregate, with a target density of $2300 \pm 100 \mathrm{~kg} / \mathrm{m}^{3}$. The other 9 mixes were termed as light weight aggregate concrete (LWAC) with a target density of $1950 \pm 100 \mathrm{~kg} / \mathrm{m}^{3}$. The LWAC mixes were similar to the NC mixes except that the volume of coarse aggregate was replaced with Lytag Concrete Aggregates. The mixes of each type (NC and LWAC) were designed to span a wide range of concrete slump values, encompassing stiff (slump 50 mm) to highly fluid (slump $\geq 250 \mathrm{~mm}$ ) fresh concrete mixes. To vary the workability of both the NC and LWAC concrete mixes, a poly-carboxylate ether (PCE) superplasticizer was added. Each mix name has a numeric identifier at the start followed by either NC or LWAC (e.g. 1NC), where the number corresponds to the layered specimen that the mix was subsequently used to cast (discussed further in the next section). The density of the mix constituents and their properties are presented in Table 2. All of the NC mixes contained a red mortar dye based upon powdered oxide pigments (see Tables 1 and 2). This was to clearly distinguish between the NC (which became concrete with a pink hue) and the LWAC (which was typical concrete grey) at all stages of the experimental campaign. 
Brault, A. \& Lees, J. M. (2020). Wet casting of multiple mix horizontally layered concrete elements Construction and Building Materials. 247, 118514

https://doi.org/10.1016/i.conbuildmat.2020.118514

Table 1. Concrete mix designations, constituent proportions, densities, and slump measurements.

\begin{tabular}{|c|c|c|c|c|c|c|c|c|c|c|}
\hline Mix & $\begin{array}{l}\text { Water } \\
{\left[\mathrm{kg} / \mathrm{m}^{3}\right]}\end{array}$ & $\begin{array}{l}\text { Cement } \\
{\left[\mathrm{kg} / \mathrm{m}^{3}\right]}\end{array}$ & $\mathrm{w} / \mathrm{c}$ & $\begin{array}{c}\text { Sand } \\
{\left[\mathrm{kg} / \mathrm{m}^{3}\right]}\end{array}$ & $\begin{array}{c}\text { Coarse } \\
\text { Agg. } \\
{\left[\mathrm{kg} / \mathrm{m}^{3}\right]}\end{array}$ & $\begin{array}{c}\text { Lytag } \\
{\left[\mathrm{kg} / \mathrm{m}^{3}\right]}\end{array}$ & $\begin{array}{l}\text { SP } \\
{[\%]}\end{array}$ & $\begin{array}{c}\text { Red } \\
\text { Dye } \\
{\left[\mathrm{kg} / \mathrm{m}^{3}\right]}\end{array}$ & $\begin{array}{l}\text { Density } \\
{\left[\mathrm{kg} / \mathrm{m}^{3}\right]}\end{array}$ & $\begin{array}{l}\text { Slump } \\
\text { [mm] }\end{array}$ \\
\hline $1 \mathrm{NC}$ & 180 & 514 & 0.35 & 605 & 1076 & 0 & 0 & 10 & 2380 & 15 \\
\hline 1LWAC & 180 & 514 & 0.35 & 605 & 0 & 538 & 1 & 0 & 1900 & 230 \\
\hline $2 \mathrm{NC}$ & 205 & 586 & 0.35 & 588 & 1045 & 0 & 0 & 10 & 2210 & 130 \\
\hline 2LWAC & 180 & 514 & 0.35 & 605 & 0 & 538 & 0 & 0 & 2040 & 80 \\
\hline 3NC & 205 & 586 & 0.35 & 588 & 1045 & 0 & 1.5 & 10 & 2300 & 270 \\
\hline 3LWAC & 180 & 514 & 0.35 & 605 & 0 & 538 & 0 & 0 & 2030 & 60 \\
\hline 4NC & 205 & 586 & 0.35 & 588 & 1045 & 0 & 0.3 & 10 & 2340 & 30 \\
\hline 4LWAC & 180 & 514 & 0.35 & 605 & 0 & 538 & 1.5 & 0 & 1920 & 270 \\
\hline $5 \mathrm{NC}$ & 205 & 586 & 0.35 & 588 & 1045 & 0 & 1.6 & 10 & 2200 & 275 \\
\hline 5LWAC & 180 & 514 & 0.35 & 605 & 0 & 538 & 1.5 & 0 & 1900 & 280 \\
\hline $6 \mathrm{NC}$ & 205 & 586 & 0.35 & 588 & 1045 & 0 & 0.5 & 10 & 2250 & 145 \\
\hline 6LWAC & 180 & 514 & 0.35 & 605 & 0 & 538 & 1.5 & 0 & 1980 & 275 \\
\hline 7NC & 205 & 586 & 0.35 & 588 & 1045 & 0 & 1.8 & 10 & 2200 & 265 \\
\hline 7LWAC & 180 & 514 & 0.35 & 605 & 0 & 538 & 0.3 & 0 & 1880 & 220 \\
\hline 8NC & 180 & 514 & 0.35 & 605 & 1076 & 0 & 0 & 10 & 2380 & 20 \\
\hline 8LWAC & 150 & 429 & 0.35 & 638 & 0 & 567 & 0 & 0 & 2060 & 20 \\
\hline 9NC & 180 & 514 & 0.35 & 606 & 1076 & 0 & 1.2 & 10 & 2320 & 130 \\
\hline 9LWAC & 150 & 429 & 0.35 & 638 & 0 & 567 & 1.5 & 0 & 1940 & 135 \\
\hline
\end{tabular}

Table 2. Concrete mix constituent densities.

\begin{tabular}{cc} 
Constituent Description & Density $\left[\mathrm{kg} / \mathrm{m}^{3}\right]$ \\
\hline $\begin{array}{c}\text { Coarse Aggregate } \\
<10 \mathrm{~mm} \text {, uncrushed }\end{array}$ & 2600 \\
\hline $\begin{array}{c}\text { Lytag Concrete Aggregates (LWA) } \\
\text { 4-14 mm, uncrushed }\end{array}$ & 1300 \\
\hline $\begin{array}{c}\text { Sand } \\
60 \% \text { passing } 600 \mu \mathrm{m} \text { sieve, }<4 \mathrm{~mm}\end{array}$ & 2600 \\
\hline $\begin{array}{c}\text { Cement } \\
\text { CEM II/A-LL strength class 32.5R }\end{array}$ & 3200 \\
\hline Water & 1000 \\
\hline $\begin{array}{c}\text { Super Plasticizer (SP) } \\
\text { Polycarboxylate ether (PCE) }\end{array}$ & 1100 \\
\hline Red Concrete Dye & 3000
\end{tabular}

The mixes were designed to have a low water to cement ratio (w/c) of 0.35 , as the effectiveness of SP decreases with increasing w/c ratios [28]. The NC mixes were designed using the Building Research Establishment (BRE) mix design method [29] to produce slump values between 30-60 mm. The LWAC mixes were also designed using the BRE method assuming normal aggregates but to achieve lower slump values of 10-30 mm. For the LWAC mixes, the volume fraction assigned to coarse aggregates in the design process was replaced with the equivalent volume of light weight aggregates. It should be noted that the LWAC mixes 
Brault, A. \& Lees, J. M. (2020). Wet casting of multiple mix horizontally layered concrete elements Construction and Building Materials. 247, 118514

https://doi.org/10.1016/i.conbuildmat.2020.118514

were designed for a slightly stiffer slump range, as the more spherical shape of the light weight aggregates was expected to lead to more workable concrete; this was done as a correction effort. It was found through preliminary studies performed by the authors that by gradually adding SP to these baseline mixes, slump values ranging from $<50 \mathrm{~mm}$ to $>250 \mathrm{~mm}$ could be achieved without segregation, which is indeed an issue associated with the overdosing of SP [27]. This enabled the normal and light weight mixes to be designed for the full range of slump values while maintaining the same w/c ratio and mix composition. However, for some of the stiffer mixes, 1NC, 8NC, 9NC, 8LWAC, and 9LWAC, a slight water content reduction was still necessary.

The NC mixes were made in an inclined drum mixer and the LWAC mixes were made in a horizontal drum mixer. Each mix with the same numeric denotation (e.g. 1NC and 1LWAC) were made simultaneously. The slump values for each mix were measured immediately after mixing using the ASTM Abrams cone (height of $300 \mathrm{~mm}$, bottom radius of $200 \mathrm{~mm}$, and top radius of $100 \mathrm{~mm}$ ) according to the ASTM standard C143/C143M - 15a [30]. The density of each mix was measured in the fresh state by compacting the concrete into a 1 litre volume using a vibrating table and subsequently measuring its weight. The target density windows for both the NC and LWAC mixes were met with the exception of 8LWAC, which had a density that was slightly higher than the maximum target density.

Figure 2 is a plot of mix density versus slump for all 18 mixes. The mixes have been visually divided into six different zones (each containing 3 mixes) based upon both their density and their slump: Fluid LWAC and NC (slump>250 mm), Medium LWAC and NC (100 $\mathrm{mm}<$ slump $<250 \mathrm{~mm}$ ), and Stiff LWAC and NC (slump $<100 \mathrm{~mm}$ ). These designations helped inform the specimens that were fabricated for the study, which are discussed in the next section. As expected, the mixes with a lower water content (1NC, 8NC, 9NC, 8LWAC, and 
Brault, A. \& Lees, J. M. (2020). Wet casting of multiple mix horizontally layered concrete elements Construction and Building Materials. 247, 118514

https://doi.org/10.1016/i.conbuildmat.2020.118514

9LWAC) are denser than the other samples in their respective zones (e.g. 9NC versus 2NC and 6NC in the Medium NC rectangle), as the volume of binder compared to aggregates is reduced (the binder is less dense than the aggregates).

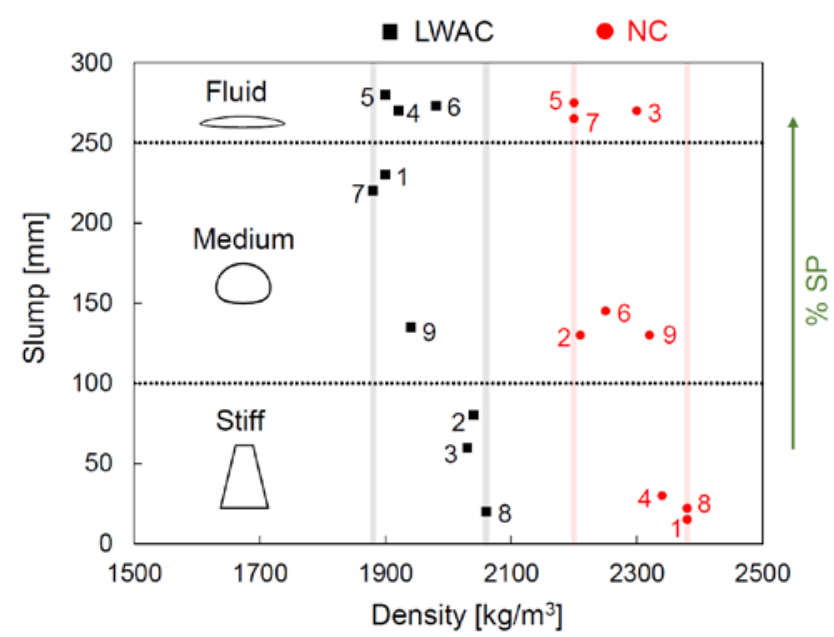

\begin{tabular}{cc} 
Mix & Compressive strength [MPa] \\
\hline 2LWAC & $51(52,50,50)$ \\
\hline 4LWAC & $50(49,52,49)$ \\
\hline 8LWAC & $49(51,49,49)$ \\
\hline 3NC & $43(44,43,43)$ \\
\hline 4NC & $41(41,40,41)$ \\
\hline 8NC & $51(52,52,49)$ \\
\hline
\end{tabular}

Figure 2. Concrete mix slump measurements versus density.

The 28-day compressive strengths of selected mixes are also shown in Figure 2. For each mix, the results of three cubes with a $100 \mathrm{~mm}$ side length were averaged, and these values are presented. Except for the addition of SP, mixes 2LWAC (51MPa) and 4LWAC (50 MPa) have the same material composition, as do mixes 3NC (43 MPa) and 4NC (41 MPa). The similarity of the compressive strengths of these comparator mixes suggests that the SP did not influence the strength. Mix 8LWAC had a similar strength to that of 4LWAC and 2LWAC but the strength of Mix 8NC was 8-10 MPa larger than that of 3NC and 4NC. As the water to cement ratios of the mixes were identical it is thought that any strength differences are a reflection of small variations due to differing mix proportions (see Table 1).

\subsection{Mix Layer Combinations}

The concrete mixes were used in combination to create two-layered specimens. Figure 3 presents a visual representation for the layered concrete specimens in the form of a graphical 
Brault, A. \& Lees, J. M. (2020). Wet casting of multiple mix horizontally layered concrete elements Construction and Building Materials. 247, 118514

https://doi.org/10.1016/i.conbuildmat.2020.118514

icon matrix. The icons are based upon the shapes of concrete slump tests (e.g. shallow ellipse for Fluid, trapezoid for Stiff), while NC mixes are pink and the LWAC are grey. The numerical indicator at the start of the designation refers to the mix number that the specimen was constructed with. For example, specimens 9A and 9B were fabricated with mixes 9NC and 9LWAC. The letter indicator following the number refers to which of the two mix density types was cast on top, where 'A' signifies that NC is on top, and ' $\mathrm{B}$ ' signifies that LWAC is on top (see Figure 3). The geometry for all specimens is shown in Figure 3. Each sample was a rectangular prism with a length of $500 \mathrm{~mm}$, a height of $100 \mathrm{~mm}$, and a width of $100 \mathrm{~mm}$, which were made by casting the concrete mixes into timber moulds. The specimens were all comprised of two horizontal layers (details of how these were cast is discussed in the next section), one of each density type and each with a height of $50 \mathrm{~mm}$.

The matrix of 18 specimens covers a large space of horizontal layering possibilities. This is seen in Figure 3, where each of the six mix types assigned in Figure 2 (e.g. Stiff NC, Fluid LWAC, etc.) is cast both above and beneath all three workability classes of the other density type. In this way, the combinations span from 4A (top left corner in Figure 3), which is a Stiff NC on top of a Fluid LWAC, to 4B (bottom right corner in Figure 3), which is a Fluid LWAC on top of a Stiff NC. Intuitively, 4A is likely to be a worst-case scenario regarding the expected deviation from a horizontal interface between mixes, while 4B is likely a best-case scenario. The other 16 combinations capture cases in between. 
Brault, A. \& Lees, J. M. (2020). Wet casting of multiple mix horizontally layered concrete elements Construction and Building Materials. 247, 118514

https://doi.org/10.1016/i.conbuildmat.2020.118514

Specimen icons
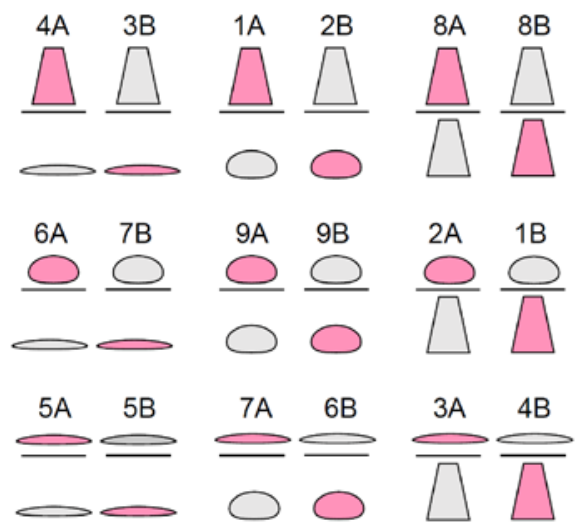

Specimen geometry

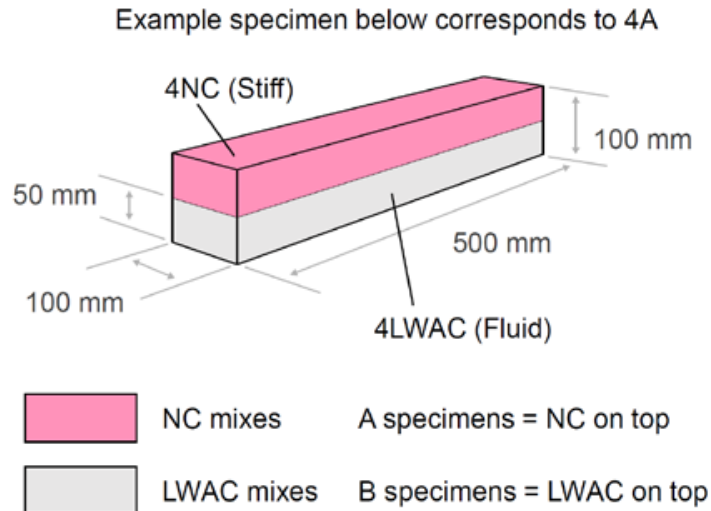

Figure 3. Layered concrete specimens.

\subsection{Layered Concrete Casting Device}

Figure 4 presents a schematic of the concrete casting device that was manufactured for the purposes of this experimental program. The device deposits controlled volumes of concrete along the longitudinal length of the rectangular specimens at a specified rate, while also being able to accommodate a wide range of concrete rheologies. Incorporating a broad scope of concrete fluidities and larger sized aggregates $(>\sim 3 \mathrm{~mm})$ was a priority in the development of this device so that ideally the mix design would not be governed by the casting process, but for the desired performance and environmental advantages.

The device had five aluminium cylinders that were vertically oriented and placed in sequence. The outer and inner diameters of the cylinders were $100 \mathrm{~mm}$ and $94 \mathrm{~mm}$, respectively. This led to the length of all five cylinders configured side-by-side to be $500 \mathrm{~mm}$, which was equal to the length of the concrete specimens. A rectangular aluminium panel was placed immediately beneath all five cylinders and could retract along the longitudinal direction. In this way, the concrete rests within the cylinders until the slider is retracted. The height of each cylinder was $100 \mathrm{~mm}$, leading to an inner cylinder volume of $\sim 0.7$ litres. To cast a layer 
Brault, A. \& Lees, J. M. (2020). Wet casting of multiple mix horizontally layered concrete elements Construction and Building Materials. 247, 118514

https://doi.org/10.1016/i.conbuildmat.2020.118514

with a height of $50 \mathrm{~mm}$ in each specimen required a compacted concrete layer volume of 2.5 litres, or one 0.5 litre volume in each of the five cylinders.
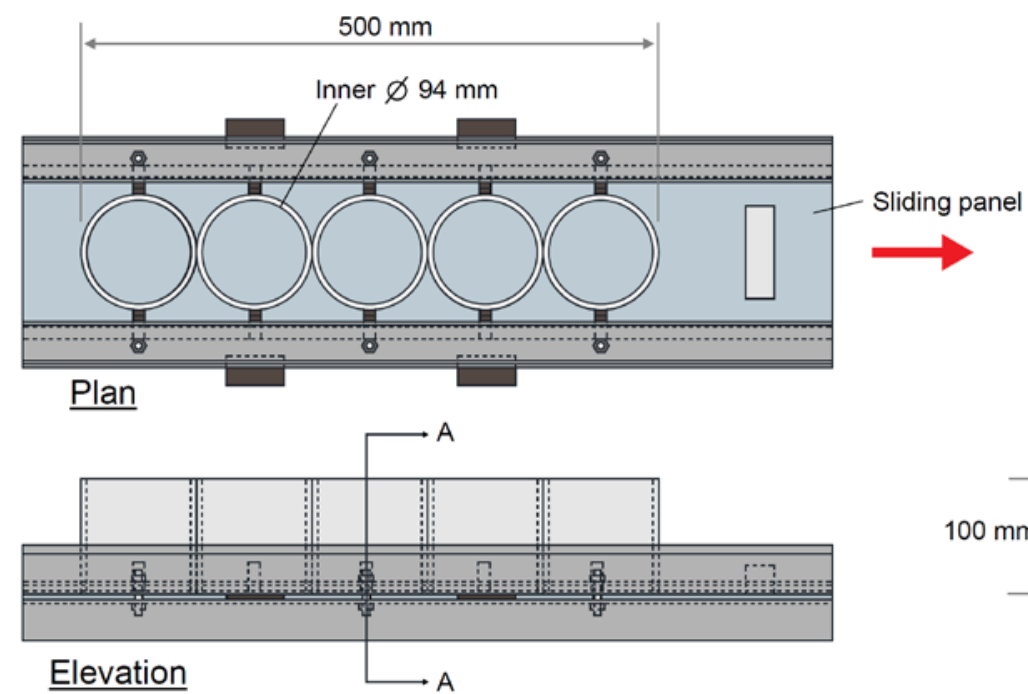

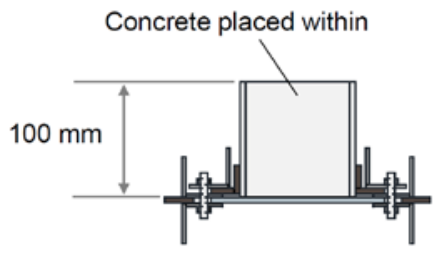

Section A-A

Figure 4. Concrete volume-control deposition device.

\subsection{Casting Procedure}

A step-by-step schematic of the casting process is presented in Figure 5. First, the lower layer mix was placed into the placing device's cylinders, with the weight of concrete that corresponds to a compacted volume of 0.5 litres in each cylinder. Once the device was filled, the sliding panel was used to deposit each volume of concrete into the timber mould at a controlled rate of 0.5 litres/second (step 1 in Figure 5). The concrete was dropped from above the form work as shown in Figure 5. Next, the bottom mix was vibrated on a vibration table until level (vibration details discussed later). The second mix layer was placed within 1 minute of when the first layer was vibrated level and was deposited on top of the bottom layer at 0.5 litres/s. The top layer was then vibrated until level with the top of the timber mould. This process was the same for all specimens and enabled each to be cast in a consistent manner despite the differences in concrete rheology and density of the mixes involved.

The entire casting process was complete within 5 minutes from the mixing of each concrete batch and the slump measurements were performed concurrently. This was to ensure 
Brault, A. \& Lees, J. M. (2020). Wet casting of multiple mix horizontally layered concrete elements Construction and Building Materials. 247, 118514

https://doi.org/10.1016/..conbuildmat.2020.118514

that the workability characterization (slump in this case) of each concrete was a good representation of the concrete's behaviour throughout the casting process. The fresh behaviour of concrete is time-dependant, and the yield stress of the concrete increases with time due to thixotropy (a reversible structuration that occurs when the concrete mix is at rest) and cement hydration (an irreversible chemical reaction). Although cement hydration commences as soon as water is mixed with cement, its effect on the concrete's yield strength only becomes apparent around 45 minutes following mixing [31]. Thus the concrete's fresh behaviour is likely not impacted by hydration during the process presented here. Thixotropy, however, does indeed influence the yield stress of the fresh concrete on a shorter time-scale, hence the motivation to perform the casting process and characterization measurements as soon as possible in this case.

\section{1: Bottom mix deposited into form}

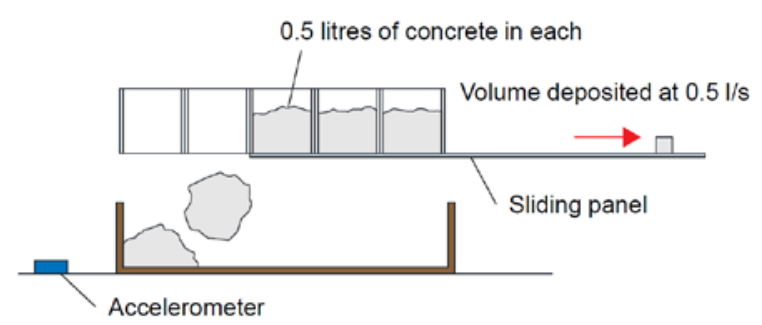

2: Bottom mix vibrated until level

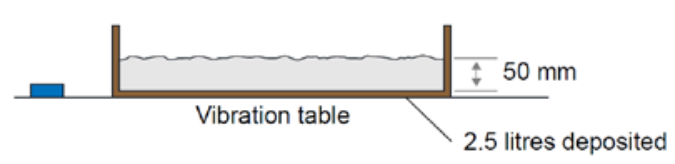

3: Top mix deposited into form

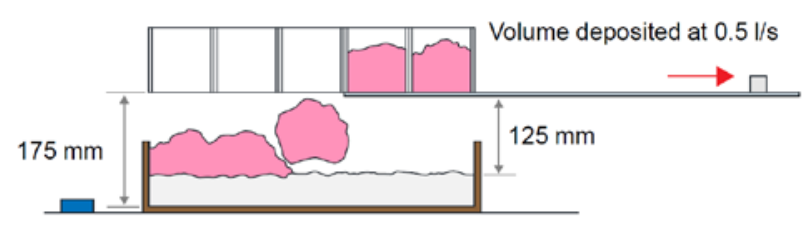

4: Specimen vibrated until top surface level

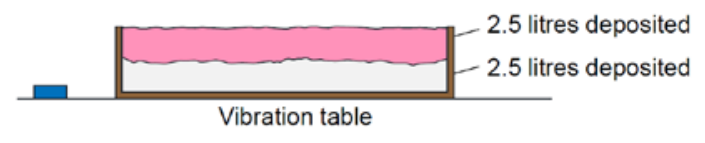

Figure 5. Casting process.

It was not possible to adjust the frequency or vibration amplitude of the vibration table used in this study. These were measured using an accelerometer (Figure 5) to be $50 \mathrm{~Hz}$ and $0.15 \mathrm{~mm}$, respectively. As previously mentioned, the duration that each concrete layer was 
Brault, A. \& Lees, J. M. (2020). Wet casting of multiple mix horizontally layered concrete elements Construction and Building Materials. 247, 118514

https://doi.org/10.1016/i.conbuildmat.2020.118514

vibrated for varied as vibration in each case was halted once the layer was visually levelled. This process was not dissimilar to that of a "Vebe Consistometer" workability test. The time that each layer was vibrated for is shown in Table 3.

Table 3. Vibration times.

Vibration time [s]

\begin{tabular}{ccccccccccccccccccccc}
\hline Specimen & $1 \mathrm{~A}$ & $1 \mathrm{~B}$ & $2 \mathrm{~A}$ & $2 \mathrm{~B}$ & $3 \mathrm{~A}$ & $3 \mathrm{~B}$ & $4 \mathrm{~A}$ & $4 \mathrm{~B}$ & $5 \mathrm{~A}$ & $5 \mathrm{~B}$ & $6 \mathrm{~A}$ & $6 \mathrm{~B}$ & $7 \mathrm{~A}$ & $7 \mathrm{~B}$ & $8 \mathrm{~A}$ & $8 \mathrm{~B}$ & $9 \mathrm{~A}$ & $9 \mathrm{~B}$ \\
\hline Bottom layer & 6 & 9 & 9 & 5 & 8 & 4 & 4 & 9 & 3 & 2 & 4 & 4 & 3 & 3 & 15 & 18 & 7 & 8 \\
\hline Top layer & 5 & 5 & 4 & 3 & 0 & 4 & 4 & 3 & 2 & 1 & 3 & 2 & 1 & 3 & 16 & 14 & 4 & 7 \\
\hline
\end{tabular}

\subsection{Measurement of Layer Profiles}

One week following the casting of each specimen, the hardened specimens were cut along three planes to provide insight on the final shape of the hardened concrete layers, as shown in Figure 6. Cut 1 was a vertical plane in the centre of each specimen along the longitudinal axis, Cut 2 was a transverse vertical plane $100 \mathrm{~mm}$ from the specimen's end immediately between two of the deposited concrete volumes, while Cut 3 ( $250 \mathrm{~mm}$ from the end) was in the centre of the $3^{\text {rd }}$ concrete volume deposited for each layer (mid-length). Each cut face was photographed with a high-resolution camera and subsequently converted into a digital schematic using CAD using a similar method to that of Torelli and Lees [26]. Two key measurements were taken (see Figure 6): 1) the maximum amount the interface boundary deviated from the mid-height (50 mm from bottom) of the specimen in the upward vertical direction (denoted as $U$ ), and 2) the maximum amount the interface boundary deviated from the mid-height of the specimen in the downward vertical direction (denoted as $L$ ). The sum of $U$ and $L$ for each cut represents the total vertical extent of the interface (denoted as Int in Figure $6)$. 
Brault, A. \& Lees, J. M. (2020). Wet casting of multiple mix horizontally layered concrete elements Construction and Building Materials. 247, 118514

https://doi.org/10.1016/i.conbuildmat.2020.118514

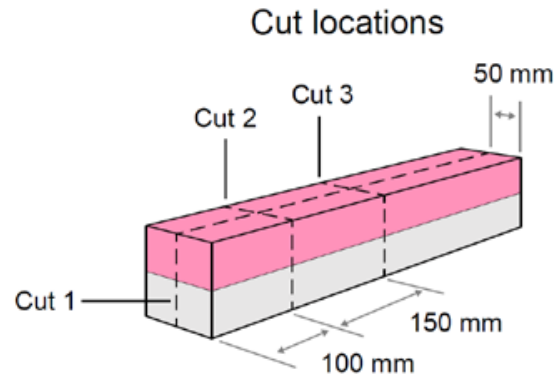

Measured indicators (Cut 1 example)

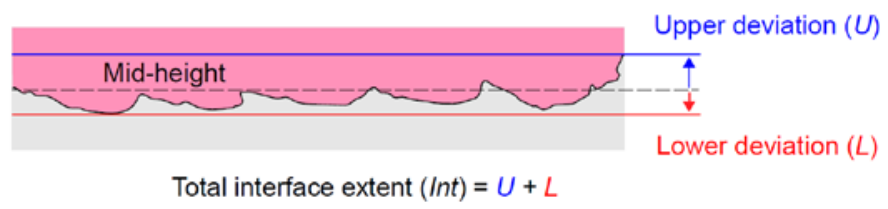

Figure 6. Specimen cut locations with example Cut 1.

\section{RESULTS AND DISCUSSION}

\subsection{Concrete Rheology}

The behaviour of fresh, or wet, concrete is often described using a Bingham material model [32], which is presented in Equation 1:

$$
\tau=\tau_{o}+\eta \dot{\gamma}
$$

where $\tau$ is the shear stress, $\tau_{\mathrm{o}}$ is the yield stress, $\eta$ is the plastic viscosity of the fluid, and $\gamma$ is the shear rate. In this case, concrete that experiences a shear stress larger than its yield stress will begin to flow. An estimate of a concrete's yield stress in the fresh state is likely to be important in understanding the flow interaction of wet concrete layers, and more specifically when flow occurs and when it is stable [26],[33].

Slump and slump flow are indicators of internal resistance mechanisms within fresh concrete, but are not pure measures of yield stress themselves. However, due to the wide-spread use and acceptance of slump and slump flow, especially in practical contexts, many relationships have been developed to predict yield stress from these measurements. For instance, Roussel [34] and $\mathrm{Hu}$ et al. [35] both proposed linear relationships to predict a concrete's yield stress. Roussel's function is suitable for slump values between $50 \mathrm{~mm}$ and 250 mm. Chidiac et al. [36] found that the yield stress predictions for slump values greater than 250 
Brault, A. \& Lees, J. M. (2020). Wet casting of multiple mix horizontally layered concrete elements Construction and Building Materials. 247, 118514

https://doi.org/10.1016/i.conbuildmat.2020.118514

mm have an undesirable amount of scatter. To address this limitation, Chidiac et al. [36] proposed the idea of estimating a concrete's yield stress using slump flow measurements and slump measurements (note: the yield stresses were measured using a BTRheom concrete rheometer). Their prediction is presented in Equation 2, for concretes spanning a wide range of slump values.

$$
\tau_{o}=\left(\frac{300-S}{540}+\frac{19800}{S_{f}^{2}}\right) \rho
$$

where $S$ is slump, $S_{f}$ is slump flow, and $\rho$ is the concrete density. As the concrete mixes in the current work also encompassed a wide range of slump values (15 mm to $280 \mathrm{~mm}$ ), Equation 2 was utilized to predict the concrete yield stress. However, slump flow values were largely only obtained for mixes of slumps greater than $250 \mathrm{~mm}$ (as is common practice), except for one mix (7LWAC) whose slump and slump flow values were measured to be $220 \mathrm{~mm}$ and $360 \mathrm{~mm}$, respectively. It was therefore necessary to relate the measured slump values to a corresponding slump flow prediction for any mix where the true slump flow was not measured. Equation 3 [37] was used for this purpose.

$$
S=300-\frac{10000000}{S_{f}^{2}}
$$

This relationship is plotted in Figure 7a along with the experimental data from the 7 mixes where slump flow was indeed measured in this work. Figure 7a shows good agreement with the measured data, thus Equation 3 was used to predict slump flow from the slump measurements for the remaining 11 mixes. With slump values and slump flow values (7 mixes measured, 11 predicted) for all 18 mixes, Equation 2 was then used to estimate the yield stress of all 18 mixes, and these yield stresses are shown in Figure 7b. The relationship between slump and yield stress is broadly linear. However, it can be seen that the NC mixes show higher yield stress values for the same slump. This makes sense as the density of the mix is the driving 
Brault, A. \& Lees, J. M. (2020). Wet casting of multiple mix horizontally layered concrete elements Construction and Building Materials. 247, 118514

https://doi.org/10.1016/i.conbuildmat.2020.118514

force causing the concrete to slump in a slump test, thus to maintain the same slump as the lighter mix, the denser mix must possess more internal resistance to flow.

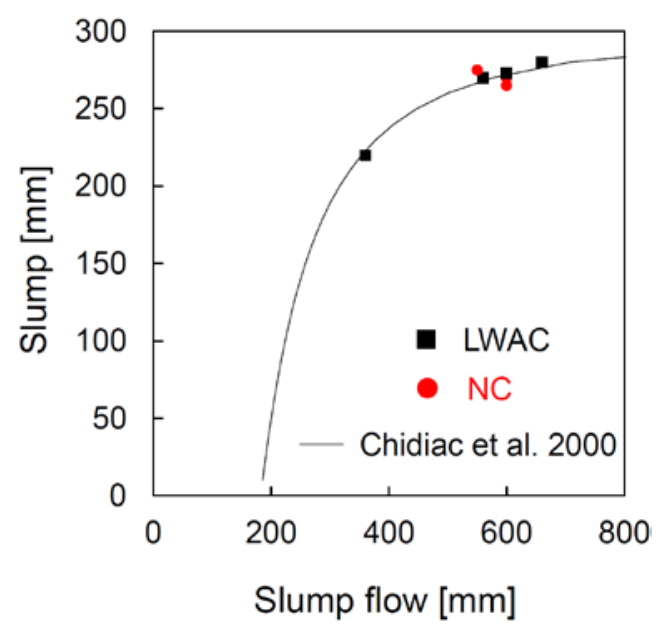

a)

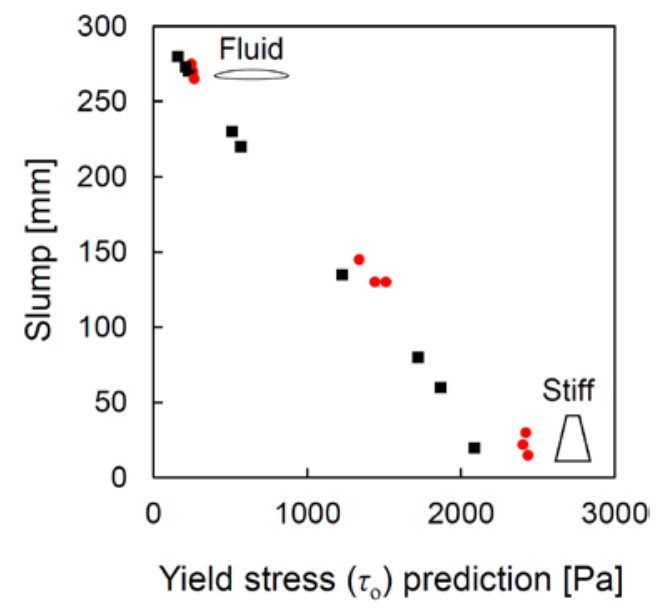

b)

Figure 7. Fresh state measurements of concrete mixes: a) slump vs. slump flow compared to Chidiac et al. [37] relationship, and b) Chidiac et al. [36] prediction of yield stress for all 18 concrete mixes.

\subsection{Hardened Layered Specimen Results}

The layered specimen results are summarised in Table 4. Schematic versions of all 54 cuts are presented (3 cuts for each of the 18 specimens) along with the measured maximum interface depth $\left(I n t_{\max }\right)$ for each specimen. The $I n t_{\max }$ term is determined for each specimen by analysing each of the three cuts and summing the largest upper deviation from mid-height $(U)$ with the largest lower deviation from mid-height $(L)$ (where $U$ and $L$ are defined in Figure 6). An $I n t_{\max }$ measure of $100 \mathrm{~mm}$ would signify that the interface reaches the top and bottom of the specimen at some point on any of the vertical planes where each of the 3 cuts were taken. By contrast, an $I n t_{\max }$ measure of $0 \mathrm{~mm}$ would mean that the interface lies exactly at the mid height of the specimen (50 mm above the bottom) on all of the vertical planes where each of the 3 cuts were taken. 
Brault, A. \& Lees, J. M. (2020). Wet casting of multiple mix horizontally layered concrete elements Construction and Building Materials. 247, 118514

https://doi.org/10.1016/i.conbuildmat.2020.118514

\begin{tabular}{|c|c|c|c|c|c|c|c|c|c|}
\hline & Cut 1 & Cut 2 & Cut 3 & Icon & $\begin{array}{l}I n t_{\max } \\
{[\mathrm{mm}]}\end{array}$ & $\begin{array}{c}\Delta \rho \\
{\left[\mathrm{kg} / \mathrm{m}^{3}\right]}\end{array}$ & $\begin{array}{c}\text { Top } \tau_{\mathrm{o}} \\
{[\mathrm{Pa}]}\end{array}$ & $\begin{array}{c}\text { Bottom } \tau_{0} \\
{[\mathrm{~Pa}]}\end{array}$ & $\begin{array}{l}\Delta \tau_{\mathrm{o}} \\
{[\mathrm{Pa}]}\end{array}$ \\
\hline $1 \mathrm{~A}$ & & & & $\frac{\Delta}{0}$ & 66 & -480 & 2433 & 509 & -1924 \\
\hline $1 \mathrm{~B}$ & & & & 음 & 10 & 480 & 509 & 2433 & 1924 \\
\hline $2 \mathrm{~A}$ & & & & 음 & 25 & -170 & 1439 & 1719 & 280 \\
\hline 2B & & & & $\frac{D}{0}$ & 32 & 170 & 1719 & 1439 & -280 \\
\hline $3 \mathrm{~A}$ & & & & $\overline{\bar{\Delta}}$ & 10 & -270 & 254 & 1866 & 1612 \\
\hline 3В & & & & $\underline{\square}$ & 52 & 270 & 1866 & 254 & -1612 \\
\hline $4 \mathrm{~A}$ & & & & $\underline{\Delta}$ & 79 & -420 & 2420 & 228 & -2192 \\
\hline $4 B$ & & & & $\overline{\bar{\Delta}}$ & 12 & 420 & 228 & 2420 & 2192 \\
\hline $5 \mathrm{~A}$ & & & & $\begin{array}{l}= \\
\end{array}$ & 79 & -300 & 246 & 157 & -89 \\
\hline $5 B$ & & & & $\underline{ }$ & 21 & 300 & 157 & 246 & 89 \\
\hline $6 \mathrm{~A}$ & & & & 으 & 55 & -270 & 1336 & 208 & -1128 \\
\hline $6 B$ & & & & $\overline{0}$ & 9 & 270 & 208 & 1336 & 1128 \\
\hline $7 \mathrm{~A}$ & & & & $\overline{0}$ & 16 & -320 & 263 & 565 & 302 \\
\hline 7B & & & & $\stackrel{0}{-}$ & 20 & 320 & 565 & 263 & -302 \\
\hline $8 \mathrm{~A}$ & & & & $\frac{\Delta}{\Delta}$ & 20 & -320 & 2402 & 2087 & -315 \\
\hline 8B & & & & $\frac{\Delta}{\Delta}$ & 16 & 320 & 2087 & 2402 & 315 \\
\hline $9 \mathrm{~A}$ & & & & $\frac{0}{0}$ & 10 & -380 & 1511 & 1226 & -285 \\
\hline 9B & & & & $\frac{0}{0}$ & 13 & 380 & 1226 & 1511 & 285 \\
\hline
\end{tabular}

Table 4. All specimen results, including CAD schematics of every cut.

Notes: For any difference (for example $\Delta \rho$ ) the properties of the top mix are subtracted from the bottom mix. 
Brault, A. \& Lees, J. M. (2020). Wet casting of multiple mix horizontally layered concrete elements Construction and Building Materials. 247, 118514

https://doi.org/10.1016/i.conbuildmat.2020.118514

The specimen mix layer icons are included in Table 4 using the symbols introduced in Figure 3. For example, a Fluid NC on a Stiff LWAC is a pink shallow ellipse on top of a grey trapezoid, which is Specimen 3A here. Table 4 also shows the difference in density between the two mixes, the yield stress of the top mix, the yield stress of the bottom mix, and the difference between the yield stress of the top and bottom mixes (top subtracted from bottom).

In general, the results in Table 4 are largely promising regarding the potential for wet casting horizontal layers. 13 of the 18 specimens have measured $I n t_{\max }$ values of $32 \mathrm{~mm}$ or less ( $3 \times$ coarse aggregate, or $\pm \sim 1.5 \times$ coarse aggregate), and 11 of those 13 have measured $I_{\text {max }}$ values of $21 \mathrm{~mm}$ or less ( $2 \times$ course aggregate, or $\pm \sim 1 \times$ coarse aggregate). Without surface finishing, the best interface boundary achievable would likely be somewhere in the order of the size of a single aggregate, indicating that respectable horizontal layering was achieved in these cases. The hardened boundaries between the top and bottom mixes for these 13 mixes are also visually suitable at the cut locations and agree with the intended layered geometry well. Lastly, and somewhat counterintuitively, 5 of the 13 passable specimens just described were cast with the denser concrete (NC) on top.

For the 5 of the 18 specimens that show interfaces with more significant deviations from the specimen mid-height (1A, 3B, 4A, 5A, and 6A), it can be seen that the interface shape fluctuates above and below mid-height. Numerically, the $\operatorname{Int}_{\max }$ term for all of these 5 specimens is also larger than $50 \mathrm{~mm}$. Four of these have a noticeably similar interface shape in Cut 1 (1A, 3B, 4A, and 6A), where the casting process of dropping 5 discrete concrete volumes along the length of the specimen for each layer (see Figure 5) appears to be imprinted in the boundary between the two mixes. These 4 specimens are thus clearly impacted by the specific deposition technique employed here, and will be referred to as "deposition influenced" from here on. These specimens have large negative yield stress differences (all more negative than - $1000 \mathrm{~Pa}$ ) 
Brault, A. \& Lees, J. M. (2020). Wet casting of multiple mix horizontally layered concrete elements Construction and Building Materials. 247, 118514

https://doi.org/10.1016/i.conbuildmat.2020.118514

when compared to the others. Specimen 5A, another with an Int $t_{\max }$ term larger than $50 \mathrm{~mm}$, has an interface shape that appears more random and less periodic. Additionally, Specimen 5A has a negative yield stress difference of only $89 \mathrm{~Pa}$, the lowest negative difference for any specimen. The driving factors leading to the inaccurate interface boundary for 5A are likely to be due to the fact that both concrete mixes involved are highly fluid, and the denser mix is on top.

To further investigate what appears to be affecting the interface boundary, the $\operatorname{Int}_{\max }$ measurements are plotted against various parameters in Figure 8. Int $\max _{\max }$ is plotted against the yield stress of the bottom mix in Figure 8a, as this is a measure of the bottom layer's resistance to flow, and thus potentially the loss of a desired interface geometry. Figure 8a shows that if the yield stress of the bottom layer is high (say, above the 1000 Pa mark on the $x$ axis), the Int $t_{\max }$ reduces. However, in the portion left of the 1000 Pa mark on the $\mathrm{x}$ axis, large scatter can be observed, with large $\mathrm{Int}_{\max }$ measurements ranging from $16 \mathrm{~mm}$ to $79 \mathrm{~mm}$. For fluid concretes on the bottom layer (150-300 Pa), the data points where the denser NC is on top are larger than those with LWAC on top. In Figure 8b, the x-axis is defined as the density of the top mix (assumed to be part of the driving force causing flow and undesirable interfaces) divided by the yield stress of the bottom mix (assumed to represent a resisting mechanism to flow). This appears to refine the data to a more consistent trend, where, as either the top mix density increases or the bottom mix yield stress decreases, Int $t_{\max }$ increases. There is still a significant scatter in the data though, especially in the central portion of the plot. 
Brault, A. \& Lees, J. M. (2020). Wet casting of multiple mix horizontally layered concrete elements Construction and Building Materials. 247, 118514

https://doi.org/10.1016/i.conbuildmat.2020.118514

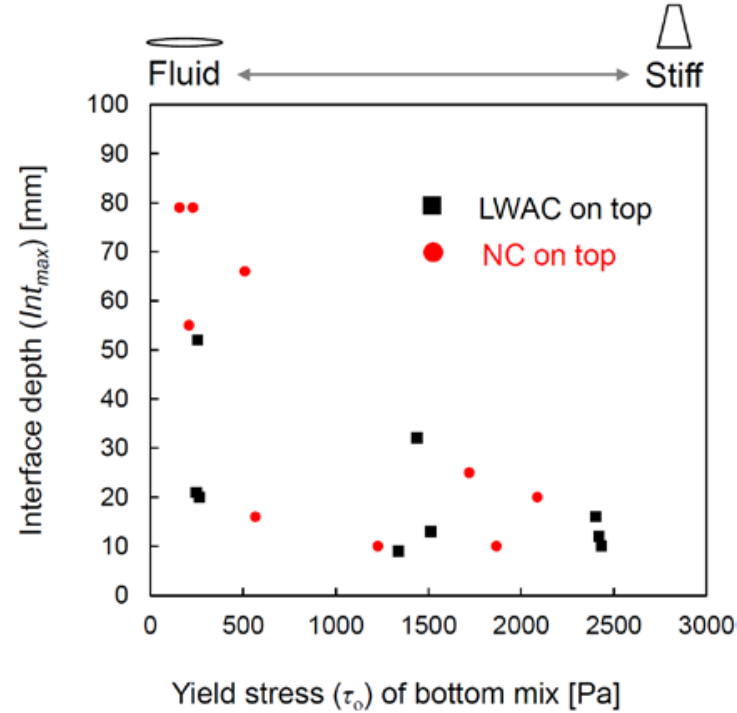

a)

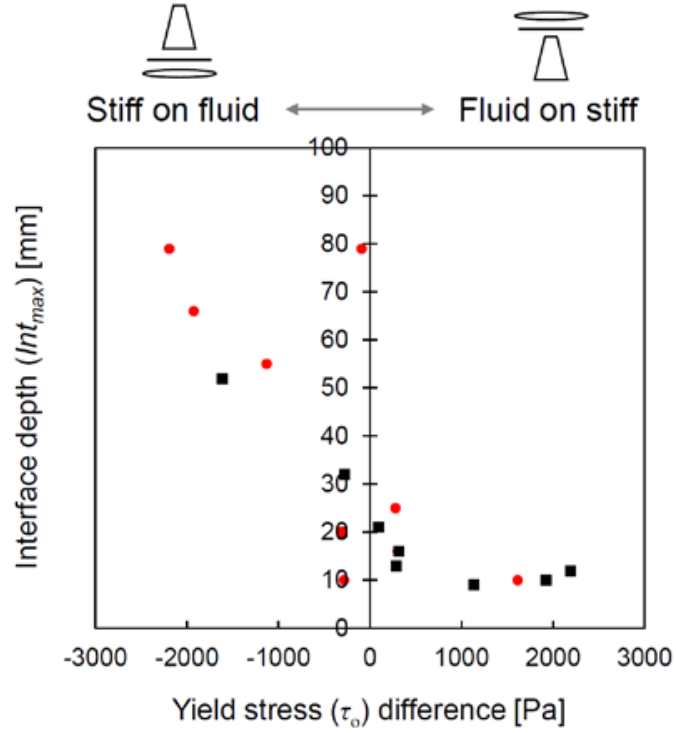

c)

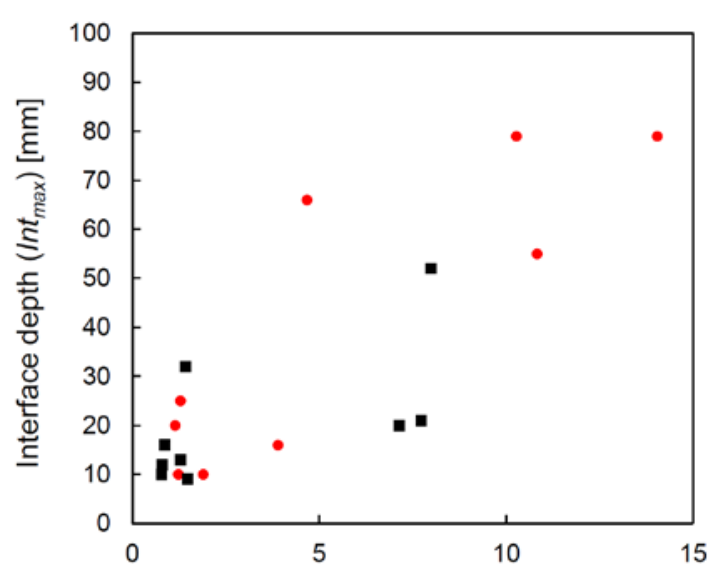

Top density/bottom yield stress $\left(\tau_{\mathrm{o}}\right)\left[\mathrm{kg} \mathrm{Pa}^{-1} \mathrm{~m}^{-3}\right]$

b)

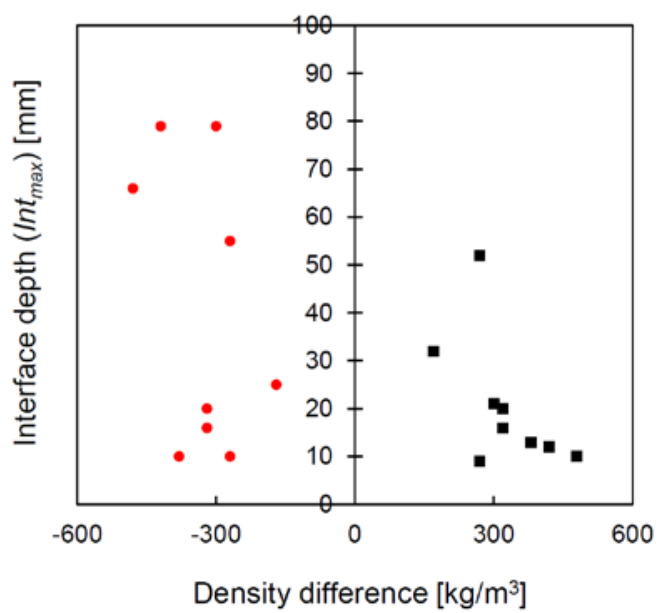

d)

Figure 8. Comparison between maximum interface depth (Int $\left.t_{\text {max }}\right)$ and various specimen properties: a) $I n t_{\max }$ Vs. yield stress of bottom layer mix, b) $I n t_{\max }$ vs. the ratio of the top mix density over the bottom mix yield stress, c) $I n t_{\max }$ vs. the yield stress difference between the top and bottom mix (top subtracted from bottom), and d) $I n t_{\max }$ vs. the density difference between top and bottom mix (top subtracted from bottom).

Figure 8c focuses on the rheological differences between the top and bottom mixes.

The left hand side of the plot shows specimens with a negative yield stress difference (stiffer mix on top of a more fluid mix), while the right hand side shows the opposite. Here a vertical line on the $\mathrm{y}$-axis aligned with $0 \mathrm{~Pa}$ on the $\mathrm{x}$-axis represents cases when the yield stresses, an 
Brault, A. \& Lees, J. M. (2020). Wet casting of multiple mix horizontally layered concrete elements Construction and Building Materials. 247, 118514

https://doi.org/10.1016/i.conbuildmat.2020.118514

indicator of workability, are similar on both the top and bottom. A clearer trend is evident in Figure 8c, where the $I n t_{\max }$ measurements appear to linearly decrease from large negative yield stress differences towards a more constant plateau as the yield stress differences become positive. The one exception is the NC on top data point with an $I n t_{\max }$ value of $79 \mathrm{~mm}$ and a small yield stress difference of -89 Pa. This point corresponds to Specimen 5A, which is the specimen with the unique interface shape discussed earlier. Figure 8c also succeeds in isolating the "deposition influenced" specimens evident in Table 4 and discussed previously (1A, 3B, 4A, and 6A), as these are the 4 data points furthest left with large $I^{n} t_{\max }$ values.

Figure 8d plots the relationship between an $I_{n} t_{\max }$ and the density difference between the top and bottom mixes (top density subtracted from bottom). Although it is evident in Figure $8 d$ that the specimens with a negative density portray more $\mathrm{Int}_{\max }$ results in excess of $\sim 20 \mathrm{~mm}$, no clear trend is apparent. Many specimens with a negative density difference show equally promising Int $t_{\max }$ values as some positive density cases. Overall, Figure 8 highlights that the interplay of the rheological characteristics of both mixes is likely the main driver of interface accuracy for the density differences used here. Therefore, the yield stress parameter is further explored in the next section as a candidate for structuring a guiding framework for the wet casting of horizontal layers.

\subsection{Discussion and Proposed Framework}

Figure 9 plots the top mix yield stress against the bottom mix yield stress for all 18 specimens to map out regions of differing interface accuracy. The four corners of the plot are graphically represented with icons to help visually understand the figure. The top right corner is where the top and bottom mixes are stiff (both $\sim 2500 \mathrm{~Pa}$ ), the bottom left corner is where the top and bottom mixes are fluid (both $<400 \mathrm{~Pa}$ ), the bottom right is where the top is fluid and the bottom is stiff, and the top left corner of the plot is where the top mix is stiff and the bottom 
Brault, A. \& Lees, J. M. (2020). Wet casting of multiple mix horizontally layered concrete elements Construction and Building Materials. 247, 118514

https://doi.org/10.1016/i.conbuildmat.2020.118514

mix is fluid. To act as a guide, vertical and horizontal lines are plotted at the $400 \mathrm{~Pa}$ marks, which is a value that Banfill [38] provides as a common yield stress for flowable concretes. Lastly, the size of each data point is proportional to the $I n t_{\max }$ measurement for each specimen to aid in interpreting trends. Figure 9 will be discussed further in the sections to follow.

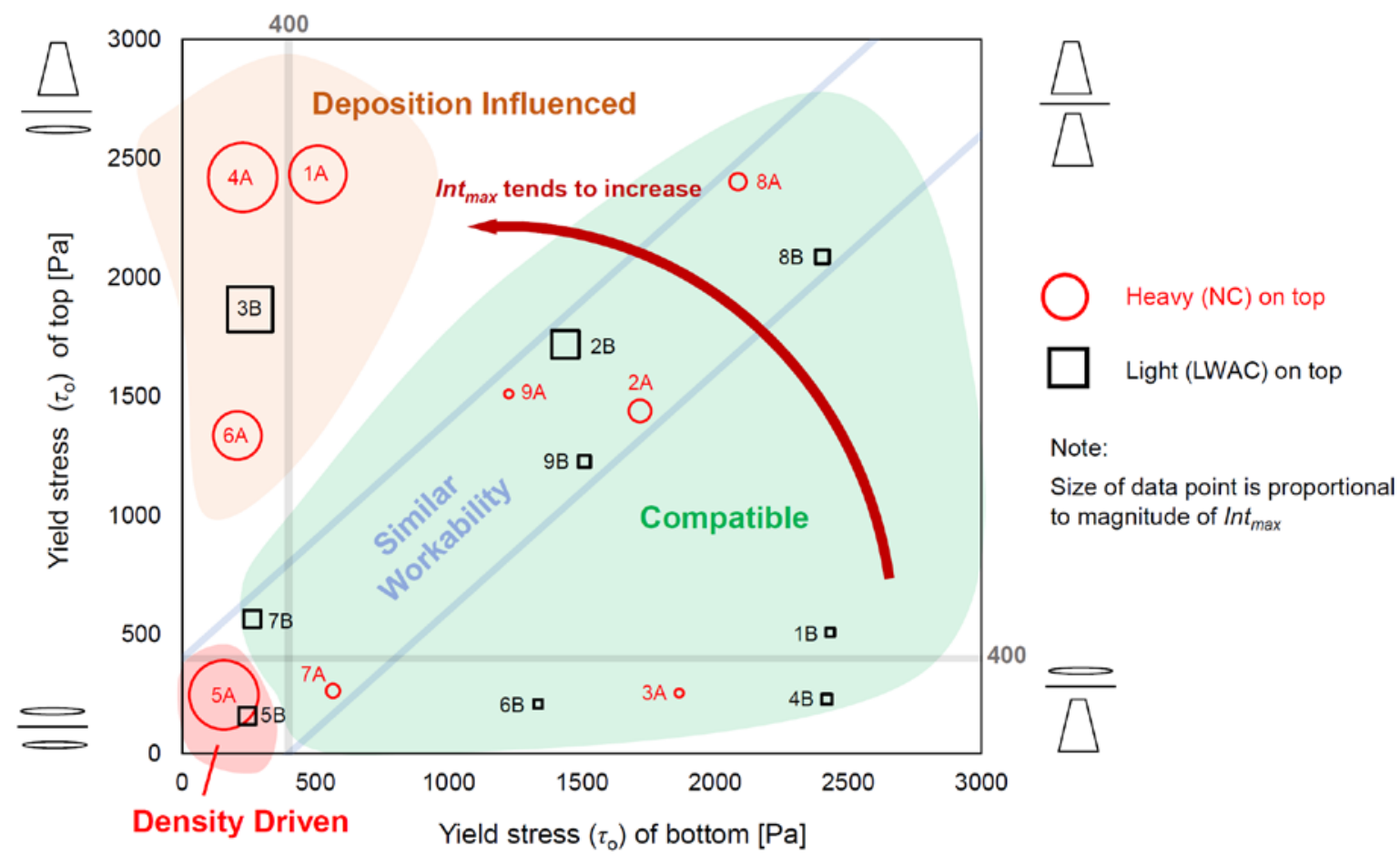

Figure 9. Yield stress of top mix vs yield stress of bottom mix with zones of different hardened interface types demarcated.

\subsubsection{Combinations of Similar Workability}

Two diagonal lines that extend from the $400 \mathrm{~Pa}$ marks on both axes towards the top right corner of the plot have been superposed on Figure 9. This highlights a "similar workability" band where the yield stresses of the top and bottom mixes are similar (difference $<400 \mathrm{~Pa}$ ). The "similar workability" band is further isolated by plotting in Figure 10 the Int max $_{\text {m }}$ value against the average yield stress of both the top and bottom mixes for Specimens 2A, 2B, 5A, 5B, 7A, 7B, 8A, 8B, 9A and 9B. 
Brault, A. \& Lees, J. M. (2020). Wet casting of multiple mix horizontally layered concrete elements Construction and Building Materials. 247, 118514

https://doi.org/10.1016/i.conbuildmat.2020.118514
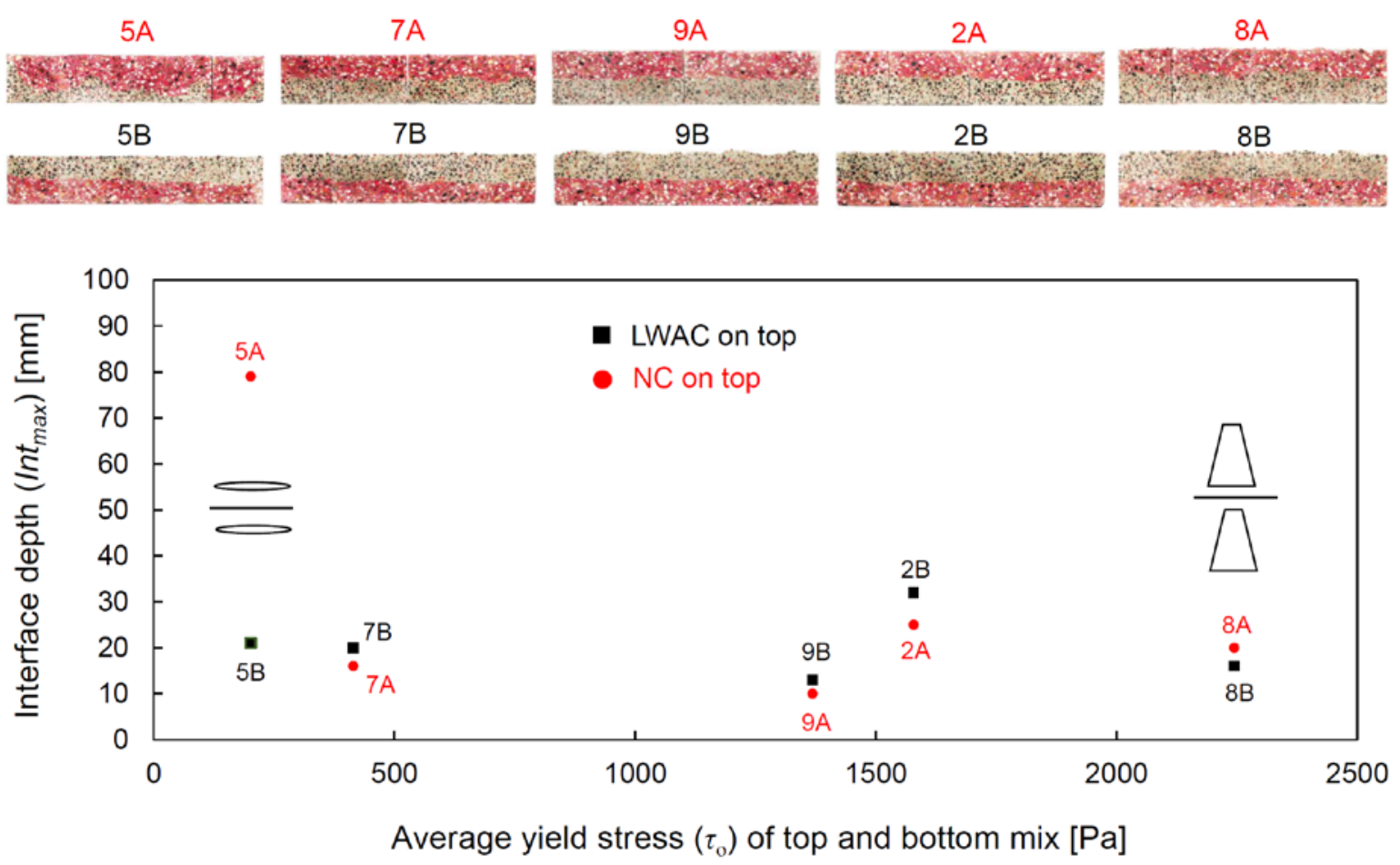

Figure 10. Interface depth $\left(I n t_{\max }\right)$ vs the average yield stress of both mixes for any specimen with similar workability on top and bottom (yield within $400 \mathrm{~Pa}$ of each other).

From Figure 10, it is observed that specimens 2A/B, 7A/B, 8A/B and 9A/B have similar Int $t_{\max }$ values (32 mm or less) and the results are fairly consistent regardless of whether the LWAC was on the top or bottom layer. In contrast, Specimen $5 \mathrm{~A}$ has an $\mathrm{Int}_{\max }$ of $79 \mathrm{~mm}$ and this is $\sim 3$ times larger than 5B. The yield stresses of the concretes in Specimens 5A and 5B are both below $250 \mathrm{~Pa}$. In this yield stress range, the density impacts the interface geometry and this zone is denoted as being "density driven” in Figure 9. When the lighter LWAC concrete $\left(1900 \mathrm{~kg} / \mathrm{m}^{3}\right)$ is cast on top of the denser NC concrete $\left(2200 \mathrm{~kg} / \mathrm{m}^{3}\right)($ Specimen 5B) the interface deviations are limited $(<20 \mathrm{~mm})$, but when the denser material is on top (Specimen $5 \mathrm{~A}$ ) there are significant deviations. This may have parallels with a Rayleigh-Taylor instability, which occurs when a denser fluid sits on a fluid that is lighter. The instability is driven by a density 
Brault, A. \& Lees, J. M. (2020). Wet casting of multiple mix horizontally layered concrete elements Construction and Building Materials. 247, 118514

https://doi.org/10.1016/i.conbuildmat.2020.118514

difference, and the two fluids intermix in a manner such that the denser fluid penetrates beneath the initial interface plane and the lighter does the opposite. This characteristic is visually observed to be the case for the interface of 5A (Table 4 and Figure 10), which shows a uniquely irregular deformed shape compared to the others.

It should be noted that the yield stresses of both concretes in Specimen 5A are still relatively large when compared to existing literature on Rayleigh-Taylor instabilities involving yield stress fluids. For instance, Maimouni et al. [39] found that for a Newtonian top fluid layer, instabilities would occur when the yield stress of the bottom fluid was in the order of 5-10 Pa for density differences of $200-800 \mathrm{~kg} / \mathrm{m}^{3}$. The yield stress of the bottom mix in $5 \mathrm{~A}$ is an order of magnitude higher, yet an instability still appears to be evident. This is likely due to the fact that the materials are vibrated once the two concrete layers are stacked. Previous research has found that vibration reduces, or even eliminates, the yield stress of fresh concrete [40]. Vibration could therefore reduce the yield stresses of specimen 5A such that a fluid-like instability takes place.

Banfill et al. [41] found that the peak velocity of vibration needed to reduce the yield stress to zero was $\sim 0.1 \mathrm{~m} / \mathrm{s}$ for concretes with yield stresses around $200 \mathrm{~Pa}$ and up to $\sim 0.3 \mathrm{~m} / \mathrm{s}$ for stiffer concretes with yield stresses in the range of 1000-2500 Pa. The peak velocity of the vibration table used here was $0.06 \mathrm{~m} / \mathrm{s}$. Thus, according to Banfill et al.[41], the applied peak velocity would not have completely eliminated the yield stress in any of the concrete mixes used. This seems to mostly correlate with the experimental results, since if the yield stresses had approached zero, fluid-like instabilities would be expected to have been more prevalent in the specimens with the denser concrete on top. However, it appears that the applied vibration was nevertheless sufficiently strong to provoke a more fluid-like behaviour in 5A. 
Brault, A. \& Lees, J. M. (2020). Wet casting of multiple mix horizontally layered concrete elements Construction and Building Materials. 247, 118514

https://doi.org/10.1016/i.conbuildmat.2020.118514

For the particular casting process used in the current work, there appears to be a minimum threshold yield stress where a fluid instability, driven by a negative density difference, will occur. Exactly what density difference will lead to instability remains a question, although as Maimouni et al. [39] found, the likelihood of instability is expected to decrease with a decrease in density difference. The minimum threshold is also dependent on the vibration regime. For instance, if stronger vibration is applied, the threshold would move to the right in Figure 10, signifying that fluid instability may occur in mixes with higher unvibrated yield stresses than seen here. By contrast, if a very fluid concrete (yield stress range of 50-200 Pa) is layered in a level manner without any vibration, it is possible that a specimen like 5A may have instead been successful. The zone where density drives the occurrence of undesirable interface geometries for fresh horizontal layers of concrete is denoted as a "density driven” zone and is represented in Figure 9 as a red cloud in the bottom left corner. This region demarcates the combination of top and bottom yield stresses that, for this particular process, have led to fluid instabilities if a negative density difference is present.

\subsubsection{Deposition Influenced Specimens}

In Figure 9, what are referred to as "deposition influenced" specimens (1A, 3B, 4A, and 6A) can be found in the top left corner. In this region, the top concrete layer is significantly stiffer than the bottom (> 1000 Pa difference in this work). The specific concrete deposition method used here appears to have led to high Int $t_{\max }$ values with a signature deformed interface shape. Figure 11 presents a schematic of how this shape may have transpired. Figure 11c is a plot of vibration time vs. yield stress for all the concrete mixes. This vibration parameter represents the time taken for each mix to become fairly level within the mould (when cast as the specimen bottom layer). This plot shows that generally, the vibration time increases with the concrete yield stress. 
Brault, A. \& Lees, J. M. (2020). Wet casting of multiple mix horizontally layered concrete elements Construction and Building Materials. 247, 118514

https://doi.org/10.1016/i.conbuildmat.2020.118514

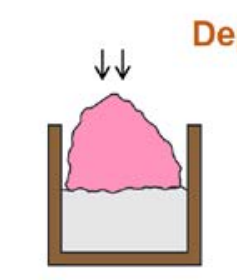

Top $\tau_{\mathrm{o}} \gg$ Bottom $\tau_{\mathrm{o}}$

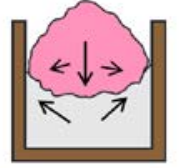

Vibration

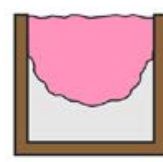

Final

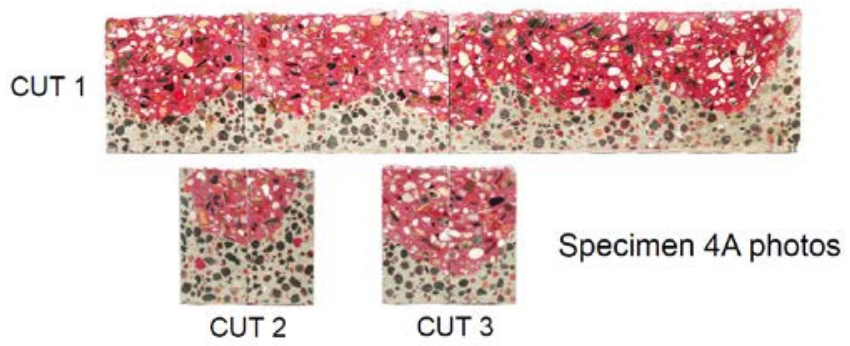

a)

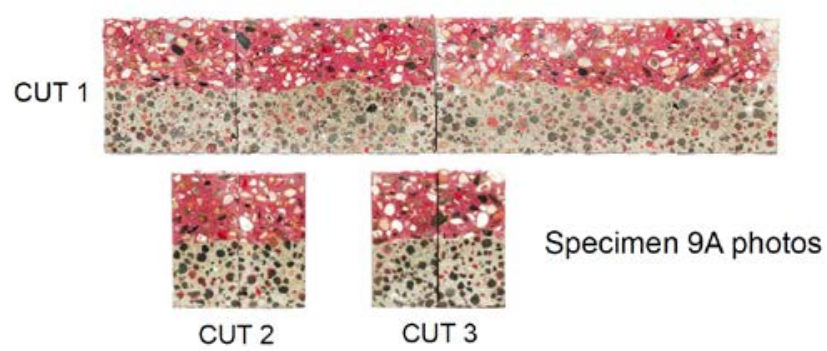

b)

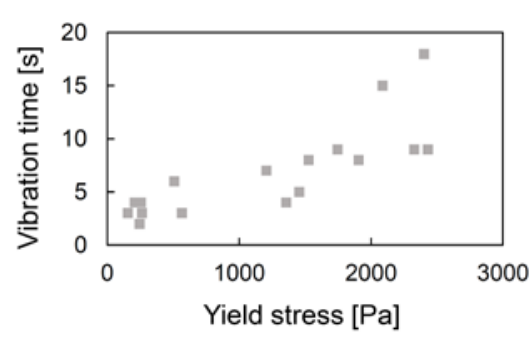

c)

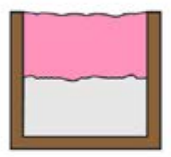

Final

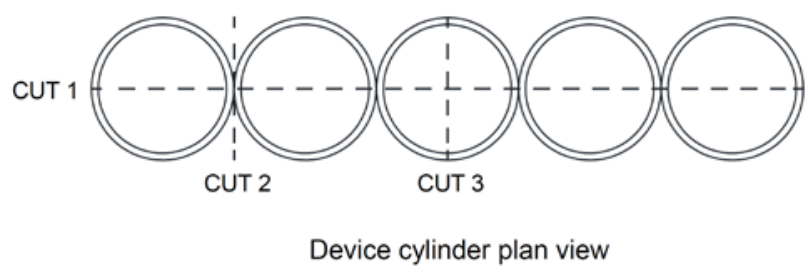

d)

Figure 11. Deposition influenced interface characteristics: a) deposition influenced schematic and images, b) compatible schematic and images, c) vibration time vs. yield stress, and d) device.

For the "deposition influenced" specimens, the stiffer top layer concrete (also with a slower vibration time) is dropped in cylindrical volumes on the bottom base layer (Figure 11a). Once all 5 cylindrical volumes are deposited, vibration occurs until the top of the specimen is level. During vibration, it is likely that centroid of each of the top layer volume shifts downward into the bottom layer, while slowly spreading outward as well. As the bottom layer is more fluid (quicker flowing), the bottom layer flows from beneath the top volume towards the edges of the volume before much (if any) of the top mass has spread to the edges. As the top layer 
Brault, A. \& Lees, J. M. (2020). Wet casting of multiple mix horizontally layered concrete elements Construction and Building Materials. 247, 118514

https://doi.org/10.1016/i.conbuildmat.2020.118514

shifts downward in the centre of the volume, the lower layer is un-confined at the edges and can travel above the intended level of the interface. The schematic shape illustrated in Figure 11a is prevalent in all the "deposition influenced" specimens, with 5 valleys along the longitudinal length (Cut 1) and 1 in each of the transverse directions (Cut 2 and Cut 3). It should be noted, however, that Cut 2 and Cut 3 typically differ, as the depth that the top layer reaches is lower for Cut 3 than Cut 2. This is because Cut 2 is between two deposited cylinders and Cut 3 is through the centreline (Figure 11d).

Specimens with mixes with similar yield stresses or with a top mix with a low yield stress were less susceptible to deposition influences (Figure 11b). In these cases, the top mix spreads outward in time to confine the bottom layer's movement. This avoids the valley and peak issue, and leads to a consistent interface height as seen in Specimen 9A in Figure 11b. The interface deviation is not dependant on the stiffness of the top layer, but on the stiffness difference between the top and bottom layers. For example, specimens 4A and 8A each have a top concrete yield stress of $\sim 2400 \mathrm{~Pa}$, but the stiffness of the bottom layer of $4 \mathrm{~A}$ is $228 \mathrm{~Pa}$ compared to 8A's bottom layer of $2087 \mathrm{~Pa}$. In 4A, the bottom layer material flows quickly to the edges of the formwork without adequate confinement from the top layer whereas in 8A the bottom layer flows at a speed more similar to the top layer which avoids this issue. The “deposition influenced” interface deviations are a direct result of how the concrete was deposited, and such influences could potentially be mitigated e.g. if the volumes deposited more closely related to their intended hardened shape (for instance, a rectangular prism vs. a cylinder).

\subsubsection{Compatible Mix Combinations}

The third region highlighted in Figure 9 is the "compatible” zone. This area covers a wide range of possible combinations in terms of mix rheology and density difference, highlighting the potential for layering concrete mixes horizontally in the wet state. 
Brault, A. \& Lees, J. M. (2020). Wet casting of multiple mix horizontally layered concrete elements Construction and Building Materials. 247, 118514

https://doi.org/10.1016/i.conbuildmat.2020.118514

Interestingly, the density difference (whether or not NC is on top or bottom) does not appear to have a significant impact on the $I n t_{\max }$ results within this region of Figure 9.

\subsubsection{Zone Boundaries}

Figure 9 maps out three regions of behaviour and the boundaries of these areas are defined by the specific results of this study. Different geometries and aspect ratios, boundary conditions, timings, deposition methods, casting processes, density difference magnitudes, and vibration parameters, would all modify the characteristics of the interplay, and the extent of the identified regions. For example, if a higher peak vibrational velocity is used, then the "density driven” bubble would be expected to extend further, and if a more precise extrusion process was used to deposit the concrete layers the "deposition influenced” zone might contract. The influence of the specimen size and selected vibration method are further considerations. Other distinct deformed interface shape results may also occur for different processes, leading to additional regions that would map onto Figure 9. The concepts that underpin Figure 9 represent a valuable framework in which to define mix combinations for horizontal wet layering.

\subsubsection{Desired Local Interface Characteristics}

Wet-on-wet casting promotes cement hydration at the boundary between mixes. This can be beneficial for mechanical performance and the mitigation of preferential substance transport. However, if the interface is visibly smooth, aggregates do not penetrate across the mix boundary and certain resistive mechanisms (such as aggregate interlock) will be compromised as a consequence. Figure 12 presents 3 different types of interfaces that were observed: 1) a smooth interface where aggregates do not pierce the boundary between mixes (Figure 12a), 2) a rough interface where aggregates penetrate the boundary (Figure 12b), and 3) an interface shape with a depth of several aggregates in height with aggregates penetrating the boundary (Figure 12c). It is of note that in all 18 specimens, the boundary between the two 
Brault, A. \& Lees, J. M. (2020). Wet casting of multiple mix horizontally layered concrete elements Construction and Building Materials. 247, 118514

https://doi.org/10.1016/i.conbuildmat.2020.118514

concrete mixes is clear, and there appears to be no blending or gradient of the mixes at the interface.

Four of the 18 specimens fabricated possessed a smooth interface like the one shown in Figure 12a. These were specimens 1B, 3A, 4B, and 6B which are all in the lower region of Figure 9 where the top concrete is much more fluid than the bottom. The interface highlighted in Figure $12 \mathrm{~b}$ is both rough and accurately located. This type of interface was exhibited by specimens in the portion of the "similar workability" diagonal band, that were outside the “density driven” zone. Hence these combinations are most likely to result in accurate interface geometries that also avoid the creation of a smooth interface plane. Finally, if the accuracy of the layering geometry is not a priority, the interface shown in Figure 12c generated due to an instability (Specimen 5A) may be the most suitable in providing interlocking between the mixes.

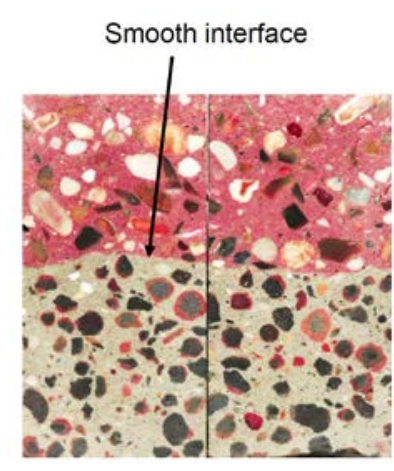

Specimen $3 A$

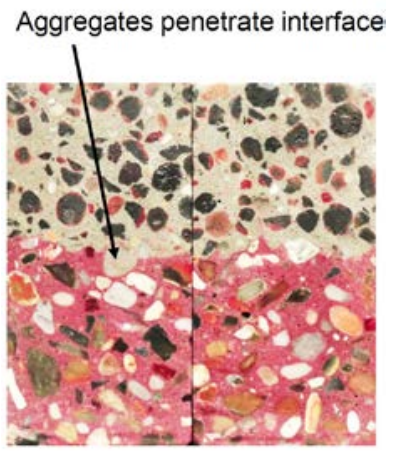

Specimen 5B

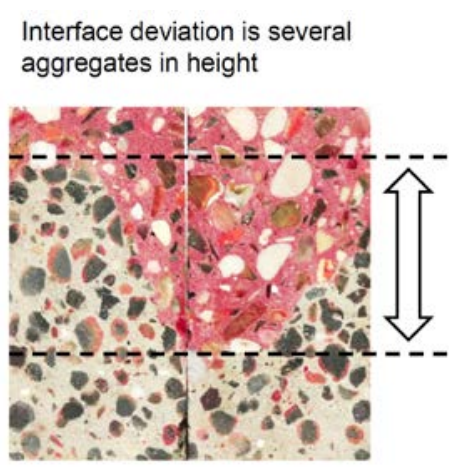

Specimen $5 \mathrm{~A}$

b)

Figure 12. Comparison between different interfaces: a) smooth interface and level, b) level interface with aggregates penetrating the boundary, and c) large Int $t_{\max }$ with aggregates penetrating the boundary.

\section{CONCLUSIONS}

The functional gradation of concrete where multiple concrete mixes are layered within a single structural element offers a strategy to mitigate global $\mathrm{CO}_{2}$ emissions. Wet-on-wet fabrication of horizontally layered FGC elements benefits from cement hydration across the 
Brault, A. \& Lees, J. M. (2020). Wet casting of multiple mix horizontally layered concrete elements Construction and Building Materials. 247, 118514

https://doi.org/10.1016/i.conbuildmat.2020.118514

interface between mixes and a quick production timeline. However, wet casting layers of different concretes within the same volume presents a key question, which is whether the different mixes will stack as intended or result in undesirable intermixing or deviations along the interface mix boundary? This is the first investigation aimed at understanding how the density and workability of layered concrete mixes dictate the resulting distribution of material of horizontal layers. The interconnectivity with the deposition process is also highlighted. Eighteen concrete specimens with two horizontal layers of different concretes were cast into formwork. The mix density was varied by including light weight aggregates. Different quantities of superplasticiser enabled a wide range of workabilities (slump $<50 \mathrm{~mm}$ to slump $>250 \mathrm{~mm}$ ) for a fixed set of constituent materials with similar mix proportions to be explored. Layer combinations whereby a denser and/or more fluid material was placed on the top or bottom layer were investigated. A bespoke casting device using controlled volume deposition was successfully developed to cast horizontally layered FGC concrete elements with a variety of concrete rheological properties. The hardened layered concrete specimens were cut into sections to inspect the internal distribution of the materials. The proximity to a flat horizontal layer geometry, as defined by the deviation of the mix interfaces from mid-height, was assessed.

The results showed that layer mix combinations of similar workability were successful unless both the top and bottom layer concretes were highly fluid (slump $>250 \mathrm{~mm}$ ). If both mixes were indeed highly fluid, a fluid-like instability would occur if the denser mix was on top of the lighter mix. Specimens that were cast with a much stiffer concrete mix on the top layer (slump of top $<<$ slump of bottom) led to an interface geometry that reflected the specific deposition technique employed here. Specimens that were cast with a more fluid concrete on top were generally successful and density differences between mixes did not appear to be a 
Brault, A. \& Lees, J. M. (2020). Wet casting of multiple mix horizontally layered concrete elements Construction and Building Materials. 247, 118514

https://doi.org/10.1016/i.conbuildmat.2020.118514

significant factor for such combinations. However, specimens with a relatively fluid top layer and stiffer bottom layer were most predisposed to smooth interfaces without any aggregates penetrating the boundary between mixes. Overall, the work provides evidence to identify appropriate concrete mix combinations to meet the intended internal geometry of horizontally layered multiple mix elements. This understanding opens up opportunities for the wet casting of functionally graded layered concrete structures to exploit lower carbon materials and enhance cement efficiency.

\section{ACKNOWLEDGEMENTS}

This project was funded by the Engineering and Physical Sciences Research Council (UK) through the EPSRC Established Career Fellowship titled "Tailored Reinforced Concrete Infrastructure: Boosting the Innate Response to Chemical and Mechanical Threats” [reference number: EP/N017668/1]. The authors would like to thank the staff of the University of Cambridge Structures Lab, and in particular the valuable work of Lorna Roberts and Phil McLaren. Additionally, the authors would like to extend their gratitude to Mar Giménez Fernández, Giacomo Torelli, and Michele W.T. Mak for their critical help with this study. All data related to this paper is available at the University of Cambridge's data repository (https://doi.org/10.17863/CAM.49680).

\section{REFERENCES}

[1] Mehta, P. K. (2001). "Reducing the environmental impact of concrete: concrete can be durable and environmentally friendly.” Concrete International, October 2001, pp. 61-66.

[2] Boden, T., Marland, G., Andres R. J., (2017). “Global, Regional, and National Fossil-fuel $\mathrm{CO}_{2}$ Emissions.” Carbon Dioxide Information Analysis Center, Oak Ridge National Laboratory, USA. 
Brault, A. \& Lees, J. M. (2020). Wet casting of multiple mix horizontally layered concrete elements Construction and Building Materials. 247, 118514

https://doi.org/10.1016/i.conbuildmat.2020.118514

[3] UN Environment and International Energy Agency. (2017). “Towards a zero-emission, efficient, and resilient buildings and construction sector.” Global Status Report 2017. 48 pp.

[4] Maalej, M., and Li, V. C. (1995). "Introduction of strain-hardening engineered cementitious composites in design of reinforced concrete flexural members for improved durability.” ACI Structural Journal, 92(2), pp. 167-176.

[5] Maalej, M., Ahmed, S. F. U., Paramasivam, P. (2003). “Corrosion durability and structural response of functionally-graded concrete beams.” Journal of Advanced Concrete Technology, 1(3), pp. 307-316.

[6] Roesler, J. Paulino, G., Gaedicke, C., Bordelon, A., Park, K. (2007). “Fracture behavior of functionally graded concrete materials for rigid pavements.” Journal of the Transportation Research Board, 2037, pp. 40-49.

[7] Li, Q., and Xu, S. (2009). "Experimental investigation and analysis on flexural performance of functionally graded composite beam crack-controlled by ultrahigh toughness cementitious composites.” Science in China Series E: Technological Sciences. 52(6), pp. 1648-1664.

[8] Bajaj, K., Shrivastava, Y., Dhoke, P. (2013) “Experimental study of functionally graded beam with fly ash.” Journal of the Institution of Engineers Series A. 94(4), pp. 219-227.

[9] Herrmann, M., Sobek, W. (2016) "Functionally graded concrete: numerical design methods and experimental tests of mass-optimized structural components.” fib Structural Concrete, 18, pp. $54-66$.

[10] Scrivener, K., Martirena, F., Bishnoi, S., Maity, S. (2018). "Calcined clay limestone cements (LC $\left.{ }^{3}\right) . "$ Cement and Concrete Research. 114(2018), pp. 49-56.

[11] Wangler, T., Lloret, E., Reiter, L., Hack, N., Gramazio, F., Kohler, M., Bernhard, M., Dillenburger, B., Buchli, J., Roussel, N., Flatt, R. (2016). “Digital Concrete: Opportunities and Challenges.” RILEM Technical Letters, 1(2016), pp. 67-75.

[12] Bos, F., Wolfs, R., Ahmed, Z., Salet, T. (2016). “Additive manufacturing of concrete in construction: potentials and challenges of 3D printing." Virtual and Physical Prototyping, 11(3), pp. 209-225. 
Brault, A. \& Lees, J. M. (2020). Wet casting of multiple mix horizontally layered concrete elements Construction and Building Materials. 247, 118514

https://doi.org/10.1016/i.conbuildmat.2020.118514

[13] Roussel, N. (2018). “Rheological requirements for printable concretes.” Cement and Concrete Research, 112, pp. 76-85.

[14] Shakor, P., Renneberg, J., Nejadi, S., Paul, G. (2017). “Optimisation of Different Concrete Mix Designs for 3D Printing by Utilising 6DOF Industrial Robot.” $34^{\text {th }}$ International Symposium on Automation and Robotics in Construction, pp. 1-8.

[15] Malaeb, Z., Hachem, H., Tourbah, A., Maalouf, T., Zarwi, N., Hamzeh, F. (2015). “3D concrete printing: machine and mix design.” International Journal of Civil Engineering and Technology, 6(6), pp. 14-23.

[16] Sika. (2011). “Sprayed Concrete Handbook.” Sika Services AG, Switzerland, 90 pp.

[17] Elliot, K. S., and Hamid, Z. A. (2017). "Modernisation mechanisation and industrialization of concrete structures.” John Wiley and Sons, UK, 482 pp.

[18] Torelli, G., Giménez Fernández, M., Lees, J. M. (2020) “Functionally graded concrete: Design objectives, production techniques, and current challenges.” Construction and Building Materials, 242, (2020), 118040

[19] fib. (2008). "Structural connections for precast buildings." fib federation international du beton, $370 \mathrm{pp}$.

[20] Denarie, E., and Brühwiler, E. (2006). “Tailored composite UHPFRC-concrete structures.” Measuring, Monitoring, and Modelling Concrete Properties, Springer, pp. 69-75.

[21] Graybeal, B. (2014). “Design and construction of field-cast UHPC connections.” Federal Highway Administration, USA, 36 pp.

[22] Nerella, V. N., Hempel, S., Mechtcherine, V. (2017). “Micro-and macroscopic investigations on the interface between layers of 3D-printed cementitious elements.” International Conference on Advances in Construction Materials and Systems, Chennai, pp. 1-10.

[23] Torelli, G., and Lees, J. M. (2020) “Functionally layered concrete elements: effect of delay between casting on the interface bond-strength.” Construction and Building Materials, 249 (2020), 118614 
Brault, A. \& Lees, J. M. (2020). Wet casting of multiple mix horizontally layered concrete elements Construction and Building Materials. 247, 118514

https://doi.org/10.1016/i.conbuildmat.2020.118514

[24] Liu, X., Yan, M., Galobardes, I., Sikora, K. (2018). “Assessing the potential of functionally graded concrete using fibre reinforced and recycled aggregate concrete.” Construction and Building Materials, 171(2018), pp. 793-801.

[25] Roussel, N. and Cussigh F. (2008). "Distinct-layer casting of SCC: The mechanical consequences of thixotropy.” Cement and Concrete Research, 38(5), pp. 624-632.

[26] Torelli, G., and Lees, J. M. (2019). “Fresh state stability of vertical layers of concrete.” Cement and Concrete Research, 120(2019), pp. 227-243.

[27] Alsadey, S. (2015). "Effect of superplasticizer on fresh and hardened properties of concrete.” Journal of Agricultural Science and Engineering, 1(2), pp. 70-74.

[28] Faroug, F., Szwabowski, J., Wild, S. (1999) “Influence of superplasticizers on workability of concrete.” Journal of Materials in Civil Engineering, 11(2), pp. 151-157.

[29] Teychenne, D. C., Franklin, R. E., Erntroy, H.C., Nicholls, J.C., Hobbs, D.W. (1997). “Design of normal concrete mixes: second edition.” Building Research Establishment (BRE). 47 pp.

[30] ASTM. (2015). "Standard test method for slump of hydraulic-cement concrete: C143/C143M 15a.” ASTM International, PA, USA, 4 pp.

[31] Roussel, N. (2007). “A thixotropy model for fresh fluid concretes: theory and applications.” $5^{\text {th }}$ international RILEM Symposium on Self-Compacting Concrete, Belgium, pp. 267-272.

[32] Tattersall, G. H., and Banfill, P. F. G (1983). “The Rheology of Fresh Concrete.” Pitman Advanced Publishing Program, London.

[33] Buswell, R. A., Leal de Silva, W. R., Jones, S. Z., Dirrenberger, J. (2018). “3D printing using concrete extrusion: a roadmap for research.” Cement and Concrete Research, 112, pp. 37-49.

[34] Roussel, N. (2006). “Correlation between yield stress and slump: comparison between numerical simulations and concrete rheometers.” Materials and Structures, 39, pp. 501-509.

[35] Hu, C., de Larrard, F., Sedran, T., Boulay, C., Bosc, F., Deflorenne, F. (1996) “Validation of BRTHEOM, the new rheometer for soft to fluid concrete.” Materials and Structures, 29(10), pp. 620-631. 
Brault, A. \& Lees, J. M. (2020). Wet casting of multiple mix horizontally layered concrete elements Construction and Building Materials. 247, 118514

https://doi.org/10.1016/i.conbuildmat.2020.118514

[36] Chidiac, S. E., Habibbeigi, F., Chan, D. (2006). "Slump and slump flow for characterizing yield stress of fresh concrete.” ACI Structural Journal, 103(6), pp. 413-418.

[37] Chidiac, S. E., Maadani, O., Razaqpur, A. G., Mailvaganam, N. P. (2000). “Controlling the quality of fresh concrete - a new approach.” Magazine of Concrete Research, 52(5), 2000, pp. 353-363.

[38] Banfill, P. F. G. (2003). “The rheology of fresh cement and concrete - a review.” $11^{\text {th }}$ International Cement Chemistry Congress, Durban, pp. 1-13.

[39] Maimouni, I., Goyon, J., Lac, E., Pringuey, T., Boujlel, J., Chateaux, X., Coussot, P. (2016). "Rayleigh-Taylor instability in elastoplastic solids: a local catastrophic process.” Physical Review Letters, 116(15), pp. 1-5.

[40] Tattersall, G. H., and Baker, P. H. (1988) “The effect of vibration on the rheological properties of fresh concrete.” Magazine of Concrete Research, 40(143), pp. 79-89.

[41] Banfill, P. F. G., Yongmo, X., Domone, P. L. J. (1999). "Relationship between the rheology of unvibrated fresh concrete and its flow under vibration in a vertical pipe apparatus.” Magazine of Concrete Research, 51(3), pp. 181-190. 